\title{
Stress cardiomyopathy associated with the first manifestation of multiple sclerosis: a case report
}

\author{
Daniel Rapp ${ }^{1}$ (D), Mirjam Keßler ${ }^{2}$, Elmar Pinkhardt ${ }^{1}$, Markus Otto ${ }^{1}$, Hayrettin Tumani ${ }^{1,3}$ and Makbule Senel ${ }^{1 *}$ (D)
}

\begin{abstract}
Background: We present a case with a close temporal association of the first diagnosis of multiple sclerosis and stress cardiomyopathy.

Case presentation: A 19-year-old man experienced severe dyspnoea. The cardiac biomarkers troponin T and NTproBNP were elevated, and transthoracic echocardiography showed basal hypokinesia. The man was diagnosed with stress cardiomyopathy after main differential diagnoses such as acute coronary syndrome, myocarditis, and pheochromocytoma were excluded. Furthermore, the patient reported vertigo and paraesthesia. Brain and spinal MRI revealed T2-hyperintense lesions with a prominent acute lesion in the pontomedullary area. Cerebrospinal fluid findings revealed a lymphocytic pleocytosis and intrathecal IgG synthesis. Serum neurofilaments were elevated. The patient was diagnosed with MS, and treatment with intravenous Methylprednisolone was initiated. The brainstem lesion due to multiple sclerosis was assumed to be the cause of stress cardiomyopathy. The patient fully recovered.

Conclusion: Stress cardiomyopathy may be linked with the first manifestation of multiple sclerosis in the presented case since pontomedullary lesions could affect the sympathetic nervous system. This case highlights the importance of neurological history and examination in young patients with unexplained acute cardiac complaints.
\end{abstract}

Keywords: Multiple sclerosis, Stress cardiomyopathy, Takotsubo cardiomyopathy, Case report, Serum NfL

\section{Background}

Stress cardiomyopathy (also takotsubo cardiomyopathy or broken-heart syndrome) is a transient loss of function of the left ventricle with characteristic wall-motion abnormalities. The most common form presents as apical ballooning [1] due to akinetic left ventricular apex. The clinical presentation, electrocardiogram (ECG) abnormalities, and elevated heart-specific biomarkers mimic acute coronary syndrome. Here, we present a case of stress cardiomyopathy in a young man associated with the first diagnosis of multiple sclerosis (MS).

\footnotetext{
* Correspondence: makbule.senel@uni-ulm.de

'Department of Neurology, University of Ulm, Oberer Eselsberg 45, 89081 Ulm, Germany

Full list of author information is available at the end of the article
}

\section{Case presentation}

A 19-year-old man without medical history experienced severe dyspnoea and was admitted to hospital as an emergency. The patient negated angina pectoris. Initial blood pressure was high $(240 / 110 \mathrm{mmHg})$, an ECG showed no relevant abnormalities, but cardiac biomarkers troponin T and NT-proBNP were elevated (27fold $(372 \mathrm{ng} / \mathrm{L})$, and 26 -fold $(2225 \mathrm{pg} / \mathrm{mL})$ of the upper normal limit (UNL), respectively). Transthoracic echocardiography showed impaired left ventricular function with basal hypokinesia. Treatment with Nebivolol and Candesartan was initiated. Cardiac magnetic resonance imaging (MRI) at day 3 showed no evidence of acute myocarditis. The left ventricular function had recovered at that time. Coronary angiography showed no evidence of coronary heart disease, thus excluding myocardial

(c) The Author(s). 2020 Open Access This article is licensed under a Creative Commons Attribution 4.0 International License, which permits use, sharing, adaptation, distribution and reproduction in any medium or format, as long as you give appropriate credit to the original author(s) and the source, provide a link to the Creative Commons licence, and indicate if changes were made. The images or other third party material in this article are included in the article's Creative Commons licence, unless indicated otherwise in a credit line to the material. If material is not included in the article's Creative Commons licence and your intended use is not permitted by statutory regulation or exceeds the permitted use, you will need to obtain permission directly from the copyright holder. To view a copy of this licence, visit http://creativecommons.org/licenses/by/4.0/ The Creative Commons Public Domain Dedication waiver (http://creativecommons.org/publicdomain/zero/1.0/) applies to the data made available in this article, unless otherwise stated in a credit line to the data. 
infarction as the reason for troponin $\mathrm{T}$ elevation and basal left ventricular hypokinesia. Endocarditis was excluded by transthoracic and transoesophageal echocardiography and repeated blood cultures. Normal blood levels of catecholamines and metanephrines excluded pheochromocytoma. The cardiac biomarkers decreased over follow-up (Fig. 1).

After the acute phase, the patient complained about vertigo. The neurological examination showed upbeat nystagmus, hyperreflexia of the lower limbs, as well as unsteady gait. On specific demand, the patient reported that he had experienced paraesthesia of the entire left side of the body and as well in the right arm and leg since 5 days before admission to the hospital. Brain and spinal MRI were performed, showing supra- and infratentorial, as well as spinal T2-hyperintense lesions (Fig. 2). One prominent lesion was found in the pontomedullary area, showing Gadolinium-enhancement and a high signal in diffusion-weighted imaging (DWI) (Fig. 2 E-H). Cerebrospinal fluid (CSF) analysis revealed a lymphocytic pleocytosis (13 leucocytes per $\mu \mathrm{L}$ ), and CSF specific oligoclonal IgG bands. Screening of potential other autoimmune or infectious diseases was negative. Serum neurofilament (sNfL) levels (measured using single-molecule array technology) were elevated while troponin $\mathrm{T}$ levels were still over the UNL (Fig. 1). Serum-Aquaporin-4- and -MOG-antibodies were negative. Evoked potential latencies showed lesions in the somatosensory pathway of the left leg as well as in the visual pathway of the right eye. The patient was diagnosed with MS according to current criteria [2] and treatment with intravenous methylprednisolone $(1 \mathrm{~g} /$ day for 5 days) was initiated. During the hospital stay, the patient fully recovered and showed no focal signs at the time of discharge. A disease-modifying treatment with Teriflunomide ( $14 \mathrm{mg} /$ day) was initiated. In follow-up examinations, 5 months later, the patient showed no abnormalities in the stress-ECG and echocardiography. Furthermore, the patient reported no events suspicious of a relapse in the first 6 months of follow-up.

\section{Discussion and conclusions}

We report a patient presenting with stress cardiomyopathy and subsequent diagnosis of MS. An extensive diagnostic work-up including ECG, echocardiography, cardiac MRI, coronary angiography, and serology, excluded main differential diagnoses, such as acute coronary syndrome, myocarditis, and pheochromocytoma. No other cause of stress cardiomyopathy was found except for an acute demyelinating pontomedullary lesion identified as the first manifestation of MS.

The exact pathophysiological mechanisms for stress cardiomyopathy are not fully understood. Unlike ischemic myocardial infarction, stress cardiomyopathy is assumed to be triggered by high levels of catecholamines as a result of emotional stress or an excessive endogenous secretion [1]. Recently, some case studies have reported a coincidence of brainstem lesions due to MS and stress cardiomyopathy [3-6]. Consistent with this, MRI imaging of the case described here revealed an acute pontomedullary Gd-enhancing lesion. It is known that some areas which regulate the autonomous nervous system are located in this area of the brainstem [7]. Pontomedullary lesions may thereby cause excessive catecholamine secretion and lead to an increased vulnerability for stress cardiomyopathy. A direct increase of Troponin by a brainstem lesion seems unlikely [8]. Furthermore, not only troponin as a heart-specific marker but also sNfL, a widely accepted marker for neuroaxonal injury $[9,10]$ detected by the single-molecule array technology, were elevated.

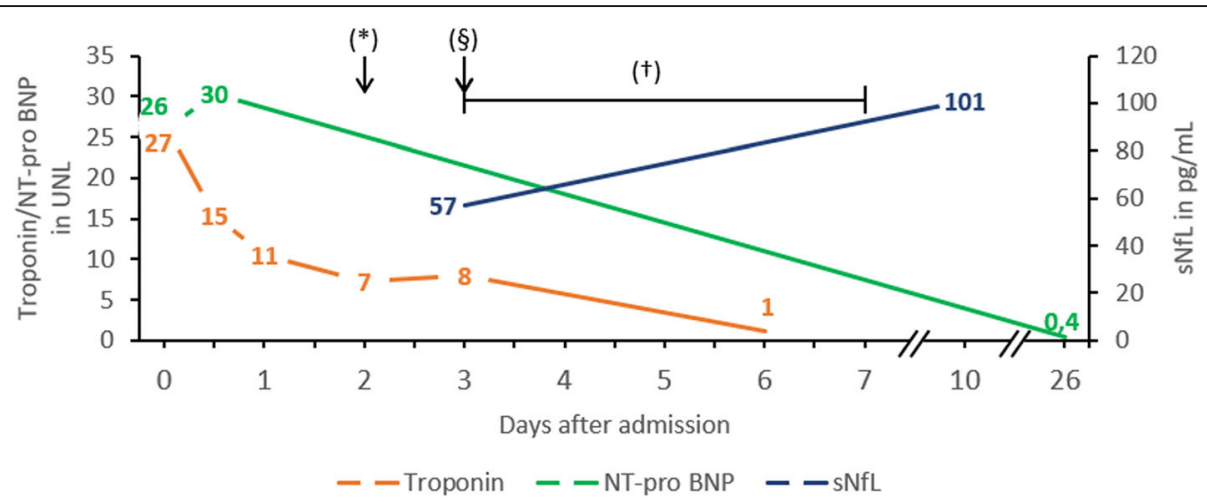

Fig. 1 Heart-specific biomarkers and serum neurofilaments Timeline of biomarkers showing multiples of the upper normal limit (UNL) in the course of the hospital stays $\mathrm{NL}=$ serum neurofilaments, BNP = brain natriuretic peptide. $\left(^{*}\right)$ brain MRI performed (§) lumbar puncture performed (†) intravenous Methylprednisolone ( $1 \mathrm{~g} /$ day for five days). Troponin and NT-pro BNP are shown in multiples of the upper normal limit (UNL, Troponin T $14 \mathrm{ng} / \mathrm{L}$, Troponin I $0.026 \mathrm{ng} / \mathrm{mL}$, NT-pro BNP $85.8 \mathrm{pg} / \mathrm{mL}$ ). Troponin T from admission until day 3 and Troponin I on day 6 


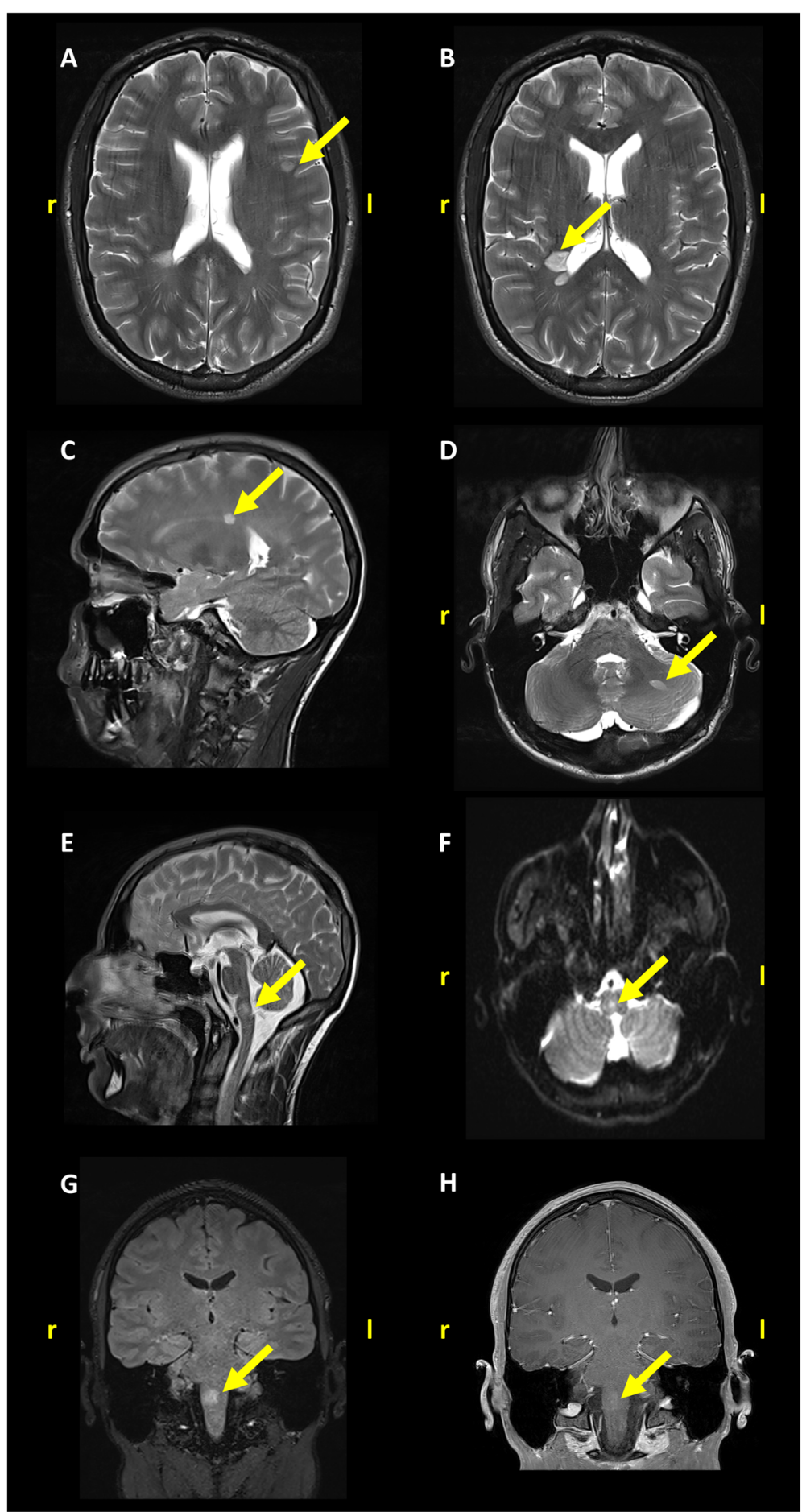

Fig. 2 Brain-MRI shows multiple supratentorial (a-c) and infratentorial (d-h), as well as one spinal (not shown) lesions suggestive of multiple sclerosis. The lesion in the medulla oblongata $(\mathbf{e}-\mathbf{g})(12 \times 10 \mathrm{~mm})$ shows Gd-enhancement and high signal on DWI. A,B,D transverse T2 TSE, C,E sagittal T2 TSE, F transverse DWI weight, G coronal T2-FLAIR, H coronal T1 VIBE

In conclusion, prospective studies are needed to confirm the hypothesis of increased risk for stress cardiomyopathy in MS patients. However, as a consequence of the mentioned cases, we recommend obtaining a detailed neurological history and examination in young patients with unexplained acute cardiac complaints. 


\section{Abbreviations}

CSF: Cerebrospinal fluid; DWI: Diffusion-weighted imaging;

ECG: Electrocardiography; Gd: Gadolinium; MRI: Magnetic resonance imaging; MS: Multiple sclerosis; NT-proBNP: N-terminal pro-B-type natriuretic peptide; sNfL: Serum Neurofilament; UNL: Upper normal limit

\section{Acknowledgements}

We thank the patient for allowing us to share his case.

\section{Authors' contributions}

Acquisition and interpretation of data, and drafted the manuscript: DR. Acquisition and interpretation of data, and critical revision of the manuscript for intellectual content: MK, EP, MO, HT. Study concept and design, acquisition and interpretation of data, and critical revision of the manuscript for intellectual content: MS. The authors read and approved the manuscript.

\section{Funding}

Not applicable.

\section{Availability of data and materials}

The datasets used and/or analysed during the current study are available from the corresponding author on reasonable request.

\section{Ethics approval and consent to participate}

Not applicable.

\section{Consent for publication}

Written informed consent was obtained from the patient for publication of this case report, individual person's data, and any accompanying images.

\section{Competing interests}

DR report no disclosures.

MK received research funding from the Hertha-Nathorff-Program.

EP has received consulting fees as an advisory board member and honoraria as a speaker from AbbVie Deutschland $\mathrm{GmbH}$ \& Co. KG, Merz

Pharmaceuticals GmbH, Medtronic GmbH, IPSEN PHARMA GmbH, UCB

Pharma GmbH, LICHER MT GmbH and has received grants from The Michael J. Fox Foundation for Parkinson's Research.

MO received honorary for consulting from Axon, Roche and Fujirebio. $\mathrm{HT}$ received funding for research projects, lectures and travel from Bayer, Biogen, Genzyme, Fresenius, Merck, Mylan, Novartis, Roche, Siemens Health Diagnostics, Teva, and received research support from Hertie-Stiftung, DMSG, BMBF and University of Ulm.

MS received consulting and/or speaker honoraria as well as trave reimbursements from Bayer, Biogen, Celgene, Merck, Roche, Sanofi Genzyme and TEVA. She received research funding from the Hertha-Nathorff-Program.

\section{Author details}

${ }^{1}$ Department of Neurology, University of Ulm, Oberer Eselsberg 45, 89081 Ulm, Germany. ${ }^{2}$ Department of Internal Medicine II, University of UIm, Albert-Einstein-Allee 23, 89081 Ulm, Germany. ${ }^{3}$ Specialty Hospital of Neurology Dietenbronn, Schwendi, Germany.

Received: 22 March 2020 Accepted: 30 April 2020

Published online: 04 June 2020

\section{References}

1. Ghadri J-R, Wittstein IS, Prasad A, Sharkey S, Dote K, Akashi YJ, et al. International expert consensus document on Takotsubo syndrome (part l): clinical characteristics, diagnostic criteria, and pathophysiology. Eur Heart J. 2018;39:2032-46. https://doi.org/10.1093/eurheartj/ehy076.

2. Thompson AJ, Banwell BL, Barkhof F, Carroll WM, Coetzee T, Comi G, et al. Diagnosis of multiple sclerosis: 2017 revisions of the McDonald criteria. Lancet Neurol. 2018;17:162-73. https://doi.org/10.1016/S14744422(17)30470-2.

3. Androdias G, Bernard E, Biotti D, Collongues N, Durand-Dubief F, Pique J, et al. Multiple sclerosis broke my heart. Ann Neurol. 2017;81:754-8. https:// doi.org/10.1002/ana.24935

4. Midaglia L, Mariño JMJ, Sastre-Garriga J, Rovira A, Vidal-Jordana A, LópezPérez MA, et al. An uncommon first manifestation of multiple sclerosis:
Tako-Tsubo cardiomyopathy. Mult Scler J. 2016;22. https://doi.org/10.1177/ 1352458516638557

5. Prestipino E, Squitieri M, Razzolini L, Pastò L, Forleo P, Amato MP. A case of Takotsubo syndrome during a multiple sclerosis brainstem relapse. Mult Scler Relat Disord. 2018;24. https://doi.org/10.1016/j.msard.2018.05.005.

6. Marrie RA, Reider N, Cohen J, Stuve O, Trojano M, Cutter G, et al. A systematic review of the incidence and prevalence of cardiac, cerebrovascular, and peripheral vascular disease in multiple sclerosis. Mult Scler J. 2015:21:318-31. https://doi.org/10.1177/1352458514564485.

7. Samuels MA. The brain-heart connection. Circulation. 2007;116:77-84. https://doi.org/10.1161/CIRCULATIONAHA.106.678995.

8. Allen Institute for Brain Science. Allen Brain Atlas API. 2020. brain-map.org/ api/index.html.

9. Khalil M, Teunissen CE, Otto M, Piehl F, Sormani MP, Gattringer T, et al. Neurofilaments as biomarkers in neurological disorders. Nat Rev Neurol. 2018;14:577-89. https://doi.org/10.1038/s41582-018-0058-z.

10. Verde F, Steinacker P, Weishaupt JH, Kassubek J, Oeckl P, Halbgebauer S, et al. Neurofilament light chain in serum for the diagnosis of amyotrophic lateral sclerosis. J Neurol Neurosurg Psychiatry. 2019;90:157-64. https://doi. org/10.1136/jnnp-2018-318704.

\section{Publisher's Note}

Springer Nature remains neutral with regard to jurisdictional claims in published maps and institutional affiliations.
Ready to submit your research? Choose BMC and benefit from:

- fast, convenient online submission

- thorough peer review by experienced researchers in your field

- rapid publication on acceptance

- support for research data, including large and complex data types

- gold Open Access which fosters wider collaboration and increased citations

- maximum visibility for your research: over $100 \mathrm{M}$ website views per year

At $\mathrm{BMC}$, research is always in progress.

Learn more biomedcentral.com/submission 